\title{
The Manufacturing of Composite Materials in the Matrix of Modified Phenol-Formaldehyde Resins
}

\author{
Volodymyr Krasinskyi ${ }^{*}$, Tomasz Jachowicz ${ }^{2}$, Ludmila Dulebova ${ }^{3}$, \\ Ivan Gajdos ${ }^{3}$, Rafał Malinowski ${ }^{4}$
}

1 Department of Chemical Technology of Plastics Processing, Lviv Polytechnic National University, Bandera 12 St., 79013 Lviv, Ukraine

2 Department of Polymer Processing, Faculty of Mechanical Engineering, Lublin University of Technology, Nadbystrzycka 36 St., 20-618 Lublin, Poland

${ }^{3}$ Department of Mechanical Engineering Technologies and Materials, Faculty of Mechanical Engineering Technical University of Košice, Masiarska 74 St., 04001 Košice, Slovakia

${ }^{4}$ Łukasiewicz Research Network - Institute for Engineering of Polymer Materials and Dyes, M. SkłodowskaCurie 55 St., 87-100 Toruń, Poland

* Corresponding author's e-mail: vkrasinsky82@gmail.com

\begin{abstract}
The work develops the method of obtaining new composite materials based on novolac phenol-formaldehyde resin with improved adhesion properties and heat resistance. The composites were obtained by chemical modification of phenol-formaldehyde resin by epoxy resin and polyvinylpyrrolidone during the hardening of the composition. The mechanism of resins modification and hardening has been determined. It is shown that due to the modification, the heat resistance and adhesive strength of the obtained enamels and coatings have significantly increased. In particular, with the polyvinylpyrrolidone content from 0.5 to $1 \mathrm{wt} \%$ and epoxy resin from 25 to $50 \mathrm{wt} \%$, the adhesive strength of the compositions increases 5-7 times.
\end{abstract}

Keywords: phenol-formaldehyde resins, epoxy resin, polyvinylpyrrolidone, modification, adhesion strength.

\section{INTRODUCTION}

Given the extensive application of phenolformaldehyde resins (PFR) in industry and private life, it is now necessary to develop new phenoplasts with high physic mechanical characteristics and a universal complex of properties for operation under various conditions. The universal applicability of these materials is connected with the broad temperature range of their hardening and the possibility of getting various operating characteristics depending on the field of their application $[2,15]$.

The phenol-formaldehyde polymers are used as glue materials, anti-corrosion coatings, and binders to produce molding powders [9]. The development of the field of polymeric glues and protective coatings requires creating new polymeric materials with given combinations of properties and, in the first place, with elevated adhesion strength and high water, chemical, and thermal resistances.

Parallel with significant advantages (accessibility of raw materials, low-cost production, easiness of preparation of the lacquer, good dielectric properties, and high chemical stability), glue compositions based on the novolac PFR also have serious shortcomings: high brittleness of the filled PFR caused by their porosity and insufficient adhesion to metals and glass [1, 13]. Therefore, the problem of developing new polymeric glue compositions and modifying the existing compositions used for gluing metals with the glass always remains quite urgent. 


\section{ANALYSIS OF RECENT RESEARCH}

The modification of phenol-formaldehyde compositions performed by using epoxy-diane resins and polymers of the $\mathrm{N}$-vinyl series guarantees the possibility of complex improvement of the properties of "cross-linked" phenoplasts via the formation of additional three-dimensional networks in the resite and owing to the presence of polar functional groups in the macrochain.

At different ratios of epoxy and phenol-formaldehyde resins, coatings with particularly high protective mechanical properties are obtained [10, $12,16]$. At the same time, it is shown that the highest chemical resistance of the coating is achieved due to the reaction of phenolic resin with diane epoxy resins of high molecular weight [10].

In work [4], bio-phenolic/epoxy polymer blends were fabricated using the hand lay-up method at different loading of bio-phenolic ( $5 \mathrm{wt} \%$, $10 \mathrm{wt} \%, 15 \mathrm{wt} \%, 20 \mathrm{wt} \%$, and $25 \mathrm{wt} \%$ ) in the epoxy matrix whereas neat bio-phenolic and epoxy samples were also fabricated for comparison. Results indicated that mechanical properties were improved for bio-phenolic/epoxy polymer blends compared to neat epoxy and phenolic. In addition, there is no sign of phase separation in polymer blends. The highest tensile, flexural, and impact strength was shown by P-20(biophenolic-20 wt $\%$ and Epoxy-80 wt $\%$ ) whereas P-25 (biophenolic- $25 \mathrm{wt} \%$ and Epoxy-75 wt \%) has the highest tensile and flexural modulus.

The authors of [18] showed that changing the crosslinking reaction temperature of epoxy-phenolic novolac resins makes it possible to adjust the porous morphology of the formed microcapsules, shell thickness, mechanical strength, and release behavior. The microcapsules surface varied from nonporous to dense small pores with increasing temperature from $40^{\circ} \mathrm{C}$ to $70^{\circ} \mathrm{C}$, but they showed decreasing tendency at higher temperature $\left(>70^{\circ} \mathrm{C}\right)$.

One of the little-studied directions of modification of PFR is using polymers based on $\mathrm{N}$-vinyl compounds. Among the polymers of the N-vinyl series of great practical interest is polyvinylpyrrolidone (PVP). It is known that PVP has an initiating effect in the polymerization of hydroxyalkylene methacrylates as an active complexing agent $[3,7]$ and also participates in the formation of new polymer matrices of liquid-structured type [14].

In work [17], authors proposed to use treated PVP fibers as reinforcing fillers of phenol-formaldehyde compositions. It is shown that the increase in adhesion and shear strength between phases, the increase in the modulus of elasticity during bending of composites occurs due to the receipt of a layer of PVP between phases.

Based on PVP, as a film-forming agent, compositions for protective coatings are obtained [8], in which from 2 to $10 \mathrm{wt} \%$ phenol-formaldehyde oligomer is introduced to increase thermal stability and water resistance. This composition is also characterized by good storage stability and forms a coating with high adhesion.

Prepolymers based on phenol-formaldehyde resins in a mixture with vinylpyrrolidone latex [6] are used for gluing all types of cord: viscose, polyamide, polyester, fiberglass, aramid, and metal cord. These compositions are stable under normal conditions and cured at $145^{\circ} \mathrm{C}$.

Thus, PVP in phenol-formaldehyde compositions can be used to improve adhesion or as a rheological additive. PFR in PVP-based compositions improve thermal and water resistance and the hardness of the coating.

This work aimed to develop new composite materials based on novolac phenol-formaldehyde resin with improved adhesion properties and heat resistance. The chemical modification of PFR by epoxy resin and PVP during the hardening of the composition solves this problem.

\section{RESEARCH METHODS}

The polymeric compositions were prepared in the following way. Phenol-formaldehyde lacquer (PFL) was obtained via dissolution at $40-50^{\circ} \mathrm{C}$ of a given mass of novolac phenol-formaldehyde resin in isopropyl alcohol. PVP was dried for $4 \mathrm{~h}$ at $60^{\circ} \mathrm{C}$. The corresponding ass of PVP was dissolved in isopropyl alcohol and thoroughly mixed with PFL and epoxy resin ED-20. Then a hardening catalyst N,N-dimethylaniline (DMA) was added.

Thermal analysis was performed using a Q1500D derivatograph of Paulik-Paulik-Erdey system [11]. The equipment makes it possible to simultaneously determine the mass loss (thermogravimetry - TG), the rate of mass loss (differential thermogravimetry - DTG), and thermal effects (DTA). The study was carried out in a dynamic mode in the air with a heating rate of $3{ }^{\circ} \mathrm{C} \mathrm{min}-1$. For the research samples weighing $0.2 \mathrm{~g}$ in powdered form were used. The reference substance was aluminum oxide. Derivatographic studies of 
the samples were performed in the temperature range of $20-900^{\circ} \mathrm{C}$.

The fine powder samples were investigated by IR spectroscopy in the medium of vaseline oil using SPECORD M-80 spectrometer (Carl Zeiss Jena, Germany), equipped with a singlehorizontal Golden Gate ATR cell. The spectra were taken after 10 scans, at a resolution of $4 \mathrm{~cm}^{-1}$, in the range of $4000-400 \mathrm{~cm}^{-1}$ [5]. Powdered composite samples were ground in an agate mortar in vaseline oil. Then they were placed between two plates with $\mathrm{KBr}$, which is transparent in this area of the IR spectrum.

To study the process of structuring compositions, prepared the specimens of compositions in the form of films in molds of polytetrafluoroethylene (GOST 10007-80) with $55 \mathrm{~mm}$ in diameter. To separate the film from the substrate, it was subjected to slight heating. The content of gel fraction was found by the extraction method of preliminarily crushed films with ethanol in a Soxhlet device.

The adhesion strength of the glue line at uniform tearing (GOST 14760-69) and shearing (GOST 14759-69) were performed on a TiraTest 2200 tensile-testing machine (Germany) with an extension rate of $50 \mathrm{~mm} / \mathrm{min}$.

\section{RESULTS AND DISCUSSION}

The predicted change of physicomechanical properties, PFR adhesive activity, is caused by the controlled process of chemical interaction between PVP+PFR and epoxy resin ED-20 or PFR and ED-20 rather than physical effects due to the unique properties of PVP. Since the resin hardening takes place at high temperatures $\left(150-180^{\circ} \mathrm{C}\right)$, taking into account exoeffect, we may expect the reaction between free hydroxy groups of PFR and lactam cycles of PVP. These predictions are confirmed by a series of physical and chemical investigation methods - Differential Thermal Analysis (DTA), IR-spectroscopy, chemical titration, etc. DTA results are represented in Figure 1.
Two endothermal effects are observed at DTA curves within the temperature range of 50$175^{\circ} \mathrm{C}$. The first one is observed within the range of $50-120^{\circ} \mathrm{C}$ and is typical for pure PFR. It corresponds to the process of resin melting. The presence of PVP in the composition causes the second endoeffect in the range of $100-125^{\circ} \mathrm{C}$. The increase of PVP amount deepens the effect and shifts it to the region of higher temperatures (Fig. 1 , curve 2). The reason is that hydrogen bonds are formed between PFR macromolecules (methoxy end-groups take part) and carbonyl groups in PVP macromolecules. Such bonds cause the origin of the ordered fluctuated network, which is destroyed at high temperatures. According to IRspectroscopy data (Table 1), the partial chemical interaction between PVP and PFR with the opening of pyrrolidone cycle and esteric bond formation is observed in the mentioned temperature range. The spectra of the compositions heated at $100^{\circ} \mathrm{C}$ for 1 hour show the absorption band at $1735 \mathrm{~cm}^{-1}$ typical of esteric bond -O-CO- in the presence of absorption band at $1040 \mathrm{~cm}^{-1}$ typical of PFR methoxy groups. With the temperature increase to $120^{\circ} \mathrm{C}$, we observe the essential increase of absorption band of esteric bond at 1735 $\mathrm{cm}^{-1}$ and decrease of absorption bands of pyrrolidone cycle and methoxy groups at 1700 and 1040 $\mathrm{cm}^{-1}$, relatively. At the same time, the intensity of

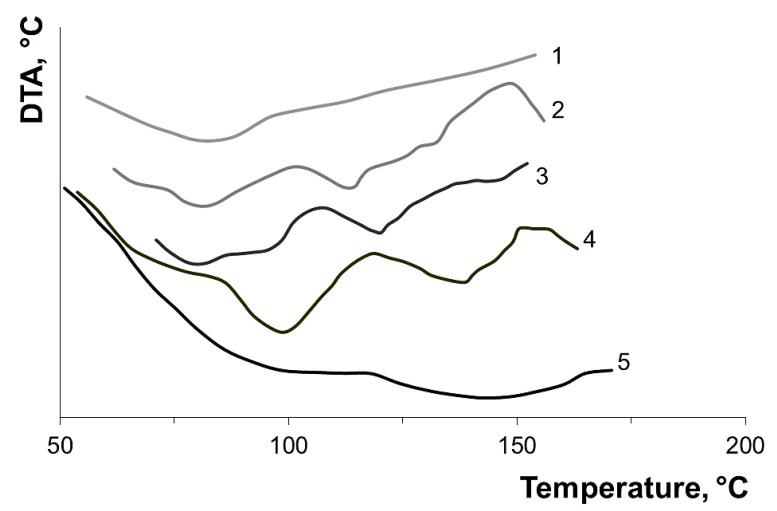

Fig. 1. DTA of the compositions: PFR of novolac type (1); PFR:PVP = 294:1 (2); PFR:PVP = 147:1 (3); PFR:PVP = 73:1 (4) and PVP (5)

Table 1. Absolute intensity of absorption band at IR-spectra of the compositions

\begin{tabular}{|c|c|c|c|c|}
\hline Compositions & $\begin{array}{c}\text { Methoxy }-\mathrm{OH} \text { - groups, } \\
\text { at } 1040 \mathrm{~cm}^{-1}\end{array}$ & $\begin{array}{c}\text { Phenolic }-\mathrm{OH}-\text { groups, } \\
\text { at } 1200 \mathrm{~cm}^{-1}\end{array}$ & $\begin{array}{c}\text { Esteric bond (-O-CO-), } \\
\text { at } 1735 \mathrm{~cm}^{-1}\end{array}$ & $\begin{array}{c}\text { Pyrrolidone cycle, at } \\
1700 \mathrm{~cm}^{-1}\end{array}$ \\
\hline PFR novolac & 5 & 25 & - & - \\
\hline PFR:PVP $=147: 1$ & 4 & 25 & 1 & 7 \\
\hline PFR:PVP $=147: 1$ at $120^{\circ} \mathrm{C}$ & 2 & 25 & 4 & 5 \\
\hline PFR:PVP $=147: 1$ at $175^{\circ} \mathrm{C}$ & - & 25 & 8 & - \\
\hline
\end{tabular}


absorption bands of phenolic hydroxyls at 1200 $\mathrm{cm}^{-1}$ is constant for all samples. It confirms the proceeding of the reaction between PVP and free methoxy groups of PFR.

The wide endoeffect appears for the PVP sample in the range of $50-175^{\circ} \mathrm{C}$ (Fig. 1, curve 5). This effect is connected with moisture loss and polymer softening. The form of endoeffect does not correspond to DTA curves for the composition samples. The effect is observed in the wider range of temperatures and is less express compared with PFR+PVP mixtures.

The chemical reaction is grafting of PFR chains to PVP with the formation of grafted copoly(vinylpyrrolidone-gr-methylphenol) copolymer accordingly to the mechanism:

The presence of methoxy groups in the PFR structure is confirmed by chemical titration and IRspectroscopy. The absorption bands in the region of $1040 \mathrm{~cm}^{-1}$ typical of methoxy groups are clearly observed in IR-spectra, as well as absorption bands at $1200 \mathrm{~cm}^{-1}$ typical of phenol hydroxyls (Table 1).

The absence of chemical interaction between PVP and phenol hydroxy groups of PFR is confirmed by model experiments with phenol. The chemical titration demonstrates the constant amount of phenol hydroxyls while mixing phenol and PVP. The reason is a subacid reaction between PVP and phenol. The absorption bands of the pyrrolidone cycle and methoxy groups are absent in the spectra of the composition PFR:PVP $=147: 1$ heated at $175^{\circ} \mathrm{C}$ for 1 hour. The maximal intensity of the absorption band of esteric bond indicates the end of chemical interaction between PFR and PVP in the mentioned temperature range.

DTA data (Figs. 2-3) of the samples hardening at $150-160{ }^{\circ} \mathrm{C}$ for $25-30 \mathrm{~min}$ indicates the proceeding of chemical interaction between PFR, PVP, and epoxy resin in the presence of hardening catalyst N,N-dimethylaniline (DMA), leading to the formation of a three-dimensional structure with high thermal stability compared with PFR hardening by urotropine. The results of the gel-fraction investigation reveal the mentioned fact (Table 2).

We studied before the interaction between phenol-formaldehyde and epoxy oligomers in the presence of PVP using model two-components systems. We did not observe the network formation at PVP introduction in the amount of 1-50 mass parts to novolac phenol-formaldehyde or epoxy resins at heating to $150-160^{\circ} \mathrm{C}$ for $0.5-1$ hour.

At the same time, the epoxy-novolac compositions are intensively crosslinked in DMA's presence as a catalyst (Table 2). It was established that the hardening degree depends upon both the ED-20 amount and the DMA catalyst amount. Therefore, at the epoxy resin content of $25 \mathrm{wt} \%$, the hardening degree is $99.4 \%$ at a DMA content of $1 \mathrm{wt} \%$. At ED-20 content of $50 \mathrm{wt} \%$, the hardening degree is $99.9 \%$. However, the most rational ratio is PFR:ED-20 $=3: 1$, at which the high hardening degree is observed at DMA content of $1 \mathrm{wt} \%$, taking into account necessary thermal stability and coating strength.

It is expected that increase in hardening temperature increases gel-fraction yield of the compositions independently of their component structure; the rational hardening temperature is $150-160{ }^{\circ} \mathrm{C}$.

The hardening degree also increases with the increase of PVP amount in the composition to $1 \mathrm{wt} \%$. The gel-fraction yield decreases with the further increase of PVP amount because the dissolved part of PVP, which does not react with PFR, has washed out the resite. Thus, PVP plays

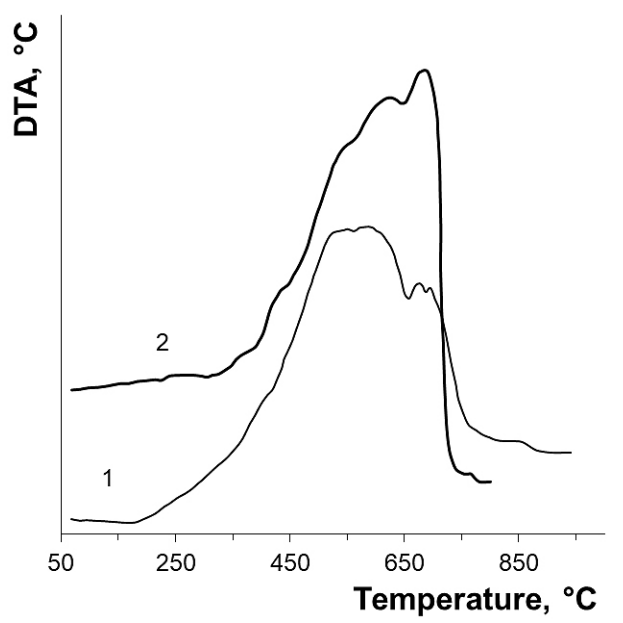

Fig. 2. DTA data of PFR with urotropine (1) and developed modified composition (2)

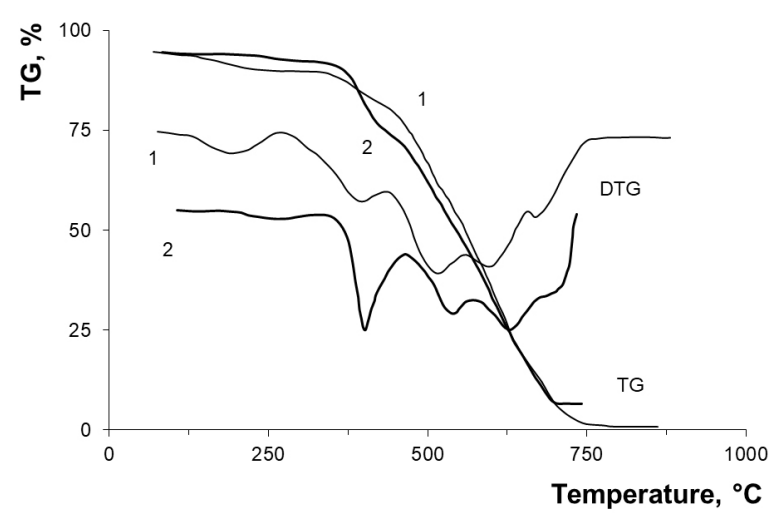

Fig. 3. TGA and DTGA of PFR urotropine (1) and developed modified composition (2) 
Table 2. Content of sol-, gel-fractions in the hardening compositions*

\begin{tabular}{|c|c|c|c|c|c|}
\hline \multicolumn{5}{|c|}{ Composition, wt } & Sol-fraction content, \\
Z, \% & $\begin{array}{c}\text { Gel-fraction content, } \\
\text { G } \%\end{array}$ \\
\hline PFR & ED-20 & PVP & DMA & 25.72 & 74.28 \\
\hline 74.25 & 25 & 0.5 & 0.25 & 16.62 & 83.38 \\
\hline 74.0 & 25 & 0.5 & 0.5 & 0.6 & 99.4 \\
\hline 73.5 & 25 & 0.5 & 1 & 0.2 & 99.8 \\
\hline 74 & 25 & 0.5 & 2.5 & 1.6 & 98.4 \\
\hline 73.5 & 25 & 0 & 1 & 0.6 & 99.4 \\
\hline 73.0 & 25 & 0.5 & 1 & 0.4 & 99.6 \\
\hline 71.5 & 25 & 1.0 & 1 & 1.5 & 98.5 \\
\hline 69.0 & 25 & 2.5 & 1 & 4.8 & 95.2 \\
\hline 97.5 & 25 & 5.0 & 1 & 97.95 & 2.05 \\
\hline 93.5 & 1 & 0.5 & 1 & 82.27 & 17.73 \\
\hline 88.5 & 5 & 0.5 & 1 & 30.07 & 69.93 \\
\hline 73.5 & 10 & 0.5 & 1 & 0.6 & 99.4 \\
\hline 48.5 & 25 & 0.5 & 1 & 0.1 & 99.9 \\
\hline
\end{tabular}

* Compositions were hardening at $150-160^{\circ} \mathrm{C}$ for $25-30 \mathrm{~min}$

a significant role in forming branched three-dimensional structures at the hardening of obtained epoxy-novolac compositions.

The described factors essentially affect the physicomechanical and adhesive properties of the composite. The effect of PVP content on adhesion has an extreme character. The adhesion has a maximum value at PVP content up to $1.0 \mathrm{wt} \%$, then the decrease of glued connection strength is observed (Table 3 ). The values of adhesion strength are in good agreement with concentrations of internal stress in glue lines.
We established that adhesion strength is maximum at ED-20:PFR $=1: 3$ at DMA content of $1 \mathrm{wt} \%$ (Table 3 ).

\section{CONCLUSIONS}

Studies confirm the possibility of chemical modification of novolac phenol-formaldehyde resins by polyvinylpyrrolidone and epoxy resin at temperatures higher than $120{ }^{\circ} \mathrm{C}$. Using differential-thermal and IR-spectroscopical analyses and

Table 3. Adhesion strength of glued connections "metal-glass" based on modified compositions*

\begin{tabular}{|c|c|c|c|c|c|}
\hline \multicolumn{4}{|c|}{ Composition, wt\%. } & \multirow{2}{*}{$\begin{array}{l}\text { Adhesion shearing } \\
\text { strength, MPa }\end{array}$} & \multirow{2}{*}{$\begin{array}{l}\text { Adhesion tearing } \\
\text { strength, } \mathrm{MPa}\end{array}$} \\
\hline PFR & ED-20 & PVP & DMA & & \\
\hline 74.25 & 25 & 0.5 & 0.25 & $1.9 \pm 0.2$ & $0.8 \pm 0.2$ \\
\hline 74 & 25 & 0.5 & 0.5 & $3.8 \pm 0.3$ & $1.3 \pm 0.2$ \\
\hline 73.5 & 25 & 0.5 & 1.0 & $5.7 \pm 0.3$ & $1.9 \pm 0.2$ \\
\hline 72 & 25 & 0.5 & 2.5 & $6.6 \pm 0.3$ & $3.2 \pm 0.3$ \\
\hline 74 & 25 & 0 & 1 & $4.8 \pm 0.3$ & $1.3 \pm 0.2$ \\
\hline 73.5 & 25 & 0.5 & 1 & $5.7 \pm 0.3$ & $1.9 \pm 0.2$ \\
\hline 73 & 25 & 1.0 & 1 & $6.4 \pm 0.3$ & $2.3 \pm 0.2$ \\
\hline 71.5 & 25 & 2.5 & 1 & $4.8 \pm 0.3$ & $1.4 \pm 0.2$ \\
\hline 69 & 25 & 5.0 & 1 & $3.1 \pm 0.3$ & $1.0 \pm 0.2$ \\
\hline 97.5 & 1 & 0.5 & 1 & $0.9 \pm 0.2$ & $0.4 \pm 0.1$ \\
\hline 93.5 & 5 & 0.5 & 1 & $1.6 \pm 0.2$ & $0.7 \pm 0.1$ \\
\hline 88.5 & 10 & 0.5 & 1 & $2.8 \pm 0.2$ & $0.9 \pm 0.2$ \\
\hline 73.5 & 25 & 0.5 & 1 & $5.7 \pm 0.3$ & $1.9 \pm 0.2$ \\
\hline 48.5 & 50 & 0.5 & 1 & $7.5 \pm 0.3$ & $2.1 \pm 0.2$ \\
\hline
\end{tabular}

\footnotetext{
* Samples were hardening at $150-160{ }^{\circ} \mathrm{C}$ for $25-30 \mathrm{~min}$
} 
model compounds, it is shown that PFR macromolecules interact with PVP with the participation of free methoxy groups of novolac phenolformaldehyde resin and carbonyl groups of PVP. The combined chemical network is formed, determining the high thermal stability of the coating. The modification of novolac PFR by polyvinylpyrrolidone and epoxy resin creates conditions for the composition hardening without urotropine. Owing to this fact, we obtained thermostable nontoxic paintwork materials with high technological effectiveness and adhesion.

\section{Acknowledgments}

The work was carried out within the framework of the National Scholarship Program of the Slovak Republic.

\section{REFERENCES}

1. Auad M.L., Nutt S.R., Pettarin V., Frontini P.M. Synthesis and properties of epoxy-phenolic clay nanocomposites. eXPRESS Polymer Letters. 2007; 1(9): 629-639.

2. Chen S., Lv S., Hou G., Huo L., Gao J. Mechanical and thermal properties of biphenyldiol formaldehyde resin/gallic acid epoxy composites enhanced by graphene oxide. Journal of Applied Polymer Science. 2015; 132(41): 42637.

3. Grytsenko O., Gajdoš I., Spišák E., Krasinskyi V., Suberlyak O. Novel Ni/pHEMA-gr-PVP composites obtained by polymerization with simultaneous metal deposition: Structure and properties. Materials. 2019; 12: 1956.

4. Ismail A.S., Jawaid M., Hamid N.H., Yahaya R., Hassan A. Mechanical and Morphological Properties of Bio-Phenolic/Epoxy Polymer Blends. Molecules. 2021; 26(4): 773.

5. Jachowicz T., Gajdoš I., Krasinskyi V. Research on the content and filler type on injection shrinkage. Advances in Science and Technology Research Journal. 2014; 8(23): 6-13.

6. Kirci B. \& Güner A. Effect of phenolic cosolutes on the main parameters, phase separation and theta temperature of dilute aqueous poly(N-vinyl-2-pyrrolidone) solutions. European Polymer Journal. 2001; 37(2): 361-365.

7. Krasinskyi V., Suberlyak O., Zemke V., Klym Y., Gaidos I. The role of polyvinylpyrrolidone in the formation of nanocomposites based on acompatible polycaproamide and polypropylene. Chemistry \& Chemical Technology. 2019; 13: 59-63.

8. Kuo S.W. \& Chang F.C. Studies of Miscibility Behavior and Hydrogen Bonding in Blends of Poly(vinylphenol) and Poly(vinylpyrrolidone). Macromolecules. 2001; 34(15): 5224-5228.

9. Mansouri N.E., Yuan Q., Huang F. Characterization of alkaline lignins for use in phenol-formaldehyde and epoxy resins. BioResources. 2011; 6(3): 2647-2662.

10. Motawie A.M. \& Sadek E.M. Adhesives and coatings based on phenolic/epoxy resins. Polymers for Advanced Technologies. 1999; 10: 223-228.

11. Paulik F., Bessenyey-Paulik E., Walther-Paulik K. Differential thermal analysis under quasi-isothermal, quasi-isobaric conditions (Q-DTA). Thermochimica Acta, 2005; 430(1-2): 59-65.

12. Pilato L. Phenolic resins: 100 Years and still going strong. Reactive and Functional Polymers. 2013; 73(2): 270-277.

13. Soltan-Dehghan M. \& Sharifi-Sanjani N. Preparation and Characterization of Phenolic Resin/Montmorillonite Nanocomposite. Iranian Journal of Polymer Science and Technology. 2012; 25(2): 83-90.

14. Suberlyak O., Krasinskiy V., Sikora J., Krzyzak A. Ammonia-free, low-toxic press-materials with improved electroinsulating properties based on modified novolak phenol-formaldehyde resin. Chemistry \& Chemical Technology. 2012; 6: 199-202.

15. Szala M., Świetlicki A., Sofińska-Chmiel W. Cavitation erosion of electrostatic spray polyester coatings with different surface finish. Bulletin of the polish academy of sciences. Technical sciences. 2021; 69(4): e137519.

16. Varlan K.E., Chervakov D.O., Sverdlikovska O.S., Zahinayko E.C., Severenchuk I.M. Modified phenolic resins and their compatibility with the components of epoxy-phenolic protective coatings. Voprosy Khimii i Khimicheskoi Tekhnologii. 2020; 1: 10-17.

17. Wen S. \& Ma J. Synergistic effect of polyvinylpyrrolidone noncovalently modified graphene and epoxy resin in anticorrosion application. High Performance Polymers. 2020; 33(2): 146-164.

18. Zhang X., Zhang L., Zhang D., Liu S., Wei D., Liu F. Mechanism of the temperature-responsive material regulating porous morphology on epoxy phenolic novolac resin microcapsule surface. Colloids and Surfaces A: Physicochemical and Engineering Aspects. 2020; 593: 124581. 